\title{
FERRAMENTAS DE COMUNICAÇÃO NA BIOÉTICA E SUA SINERGIA COM A EDUCAÇÃO AMBIENTAL
}

Thierry Betazzi Lummertz ${ }^{1}$

Marta Luciane Fischer ${ }^{2}$

Resumo: Visando mapear as ferramentas de comunicação empregadas pela bioética foi realizada uma revisão integrativa resultando em 1.767 conteúdos científicos. As pesquisas práticas prevaleceram no Brasil com questionários e entrevistas como ferramentas de prospecção, aplicação e avaliação. Embora haja confluência de valores e interesses entre a bioética ambiental e a Educação Ambiental, a disparidade nos processos legitima a sinergia das disciplinas. Uma vez que, permite trabalhar multidisciplinarmente valores de agentes e pacientes morais diante de conflitos complexos, plurais e globais. Bem como, potencializar o impacto positivo na sociedade com mudanças em prol de uma existência factível e justa para pessoas e natureza desta e de futuras gerações.

Palavras-chave: Bioética de Intervenção; Bioética na Educação; Teatro Educação; Simulação; Ferramentas Educativas.

Abstract: Communication in bioethics and its synergy with environmental education. We were the objective to map the communication tools employed by Bioethics, we carried out an integrative review resulting in 1,767 scientific contents. Practical research prevailed in Brazil with questionnaires and interviews as tools for prospecting, application, and evaluation. Although there is a confluence of values and interests between Environmental Bioethics and Environmental Education, the disparity in the processes legitimizes the synergy of the disciplines to work values of agents and moral patients with multidisciplinary in the face of complex, plural, and global moral conflicts and enhance the positive impact on society with changes in favor of a feasible and fair existence for people and nature of this and future generations.

Keywords: Bioethics of Intervention; Bioethics in Education; Education Theater; Simulation; Educational Tools.

\footnotetext{
1Pontifícia Universidade Católica do Paraná. E-mail: thierryl.bio@gmail.com, Link para o Lattes: http://lattes.cnpq.br/6301060025520592

2. Pontifícia Universidade Católica do Paraná. E-mail: marta.fischer@pucpr.br. Link para o Lattes: http://lattes.cnpq.br/3200226780923332
} 


\section{Introdução}

A bioética originou-se no meio científico concomitante à Educação Ambiental (EA) caracterizada como um campo do conhecimento sustentado pelo questionamento sobre a forma de se produzir Ciência e a necessidade de conectar as áreas do saber com valores comuns (PESSINI; BARCHIFONTAINE, 2007). Porém, a corrida para restituição econômica e política das nações após as grandes guerras mundiais demandou investimento no desenvolvimento de tecnologia, com consequentes abusos cometidos à natureza e na condução das pesquisas com seres humanos e animais (POTTER, 2016, FISCHER et al., 2017b).

Os primeiros registros do neologismo bioética transcorreu nos Estados Unidos na década de 1970 por Van Rensselaer Potter conclamando por uma Ciência da sobrevivência por meio da convergência entre as ciências biológicas e as humanidades como garantia da possibilidade de um futuro (POTTER, 2016, GOLDIM, 2006). Posteriormente, a bioética passou a ser reconhecida como área específica de conhecimento, com atuação abrangente englobando questões éticas relativas à saúde e ao meio ambiente (PESSINI; BARCHIFONTAINE, 2007). Fischer e Furlan (2018) propuseram a confluência da bioética com a EA ressaltando que embora não haja uma menção em documentos oficiais é explicita a concordância para processos que demandam reavaliação ou construção das condutas éticas. A bioética ambiental (BA) traspõe a ética ambiental no que tange a atuação prática por meio da multidisciplinaridade (FISCHER et al., 2017b,c). Portanto, se constitui de uma ferramenta para EA, uma vez que reforça a intenção de ir além da explicação dos processos naturais, normatização de condutas ou constituição de estratégias para solução de problemas. Permitindo, assim, a reavaliação de valores, crenças e concepções que permeiam os discursos ecológicos (FISCHER; FURLAN, 2017, 2018).

No Brasil as primeiras pesquisas com bioética foram veiculadas na década de 1980, coincidindo as discussões sobre direitos humanos intensificadas após o período de governo militar (PIZZANI et al., 2010). Na década seguinte foram implementados a Sociedade Brasileira de Bioética e grupos de estudo sobre os Direitos Humanos na medicina e em pesquisas, consolidando a produção científica e, consequentemente, a bioética como área de saber. No início do milênio a Organização das Nações Unidas (ONU) proclamou a Declaração Universal sobre Bioética e Direitos Humanos fortalecendo a reflexão acerca do impacto da tecnologia na sociedade e no ambiente. A citada declaração pautou suas ações baseadas em valores éticos para uma transformação social e a responsabilidade da geração presente em garantir um planeta digno às futuras gerações (ONU, 2005). Mais recentemente a Organização das Nações Unidas para a Educação, a Ciência e a Cultura (UNESCO) publicou a declaração da rede latino-americana e do Caribe para a educação em bioética enfatizando a importância de ser priorizada para que, assim as questões urgentes como precariedade da saúde, desigualdade social, 
sustentabilidade e segurança alimentar sejam discutidas e mitigadas (UNESCO, 2019).

Com quase quatro décadas de atuação, a bioética formou mundialmente especialistas, membros de conselhos e legisladores, promoveu encontros científicos e produziu um amplo material bibliográfico. Embora em essência a bioética se insira em reflexões teóricas, há um espaço factível e necessário para prática como ferramenta multi e interdisciplinar de pesquisa e formação, bem como de análise e resolução dos conflitos e dilemas morais nos campos das ciências da vida e da saúde (SCHRAMM, 2002, FISCHER; FURLAN, 2018). Enquanto a bioética norte-americana confluiu com a ideologia política liberal encontrando espaço na prática médica (PESSINI, 2007), na América Latina foi impulsionada por questionamentos referentes à desigualdade quanto ao uso e acesso à tecnologia e serviços de saúde, sendo marcada por conceitos de justiça, equidade e solidariedade (FEITOSA; NASCIMENTO, 2015). A bioética de intervenção na América Latina, e principalmente no Brasil, direcionou sua atuação para questões de saúde pública e para a reforma sanitária atribuindo à bioética um viés político (PESSINI; BARCHIFONTAINE, 2007). Devido as urgências dos países em desenvolvimento serem de difícil solução, a bioética tomou prioritariamente um caminho utópico, no qual muitos pensamentos são importantes e valorosos, mas complicados de se colocar em ação com a almejada ética da libertação, automaticamente, atrasando a prática cotidiana (FEITOSA; NASCIMENTO, 2015).

A BA compartilha com a EA fundamentações teóricas e abordagens metodológicas visando desenvolver habilidades e modificar as atitudes em relação à natureza (SATO, 2003, LOUREIRO, 2009, FISCHER; FURLAN, 2017, FISCHER et al., 2020 a,b). Contudo, demanda pesquisa, aplicação e validação de metodologias que promovam sua sinergia e, consequentemente, a educação moral e ambiental (FISCHER et al., 2017 a,c, 2019, 2020b), em especial para estudantes do ensino básico por esta fase consolidar a compreensão das consequências de tomada de decisões balizadas pela sustentabilidade ambiental, econômica e social (FISCHER et al., 2020a,b). Diferente da BA, a EA foi prontamente aceita mundialmente e imediatamente incorporada em políticas públicas e educacionais (BRASIL, 1999, FISCHER et al., 2019). No entanto se identifica a BA na sua definição legal como um processo de construção de valores sociais, conhecimento e atitudes individuais e coletivas, visando a conservação do planeta (FISCHER et al., 2020b).

Com intuito de alcançar diferentes públicos com características e linguagens próprias foram desenvolvidas ferramentas para planejamento, aplicação e avaliação da EA, tais como técnicas que envolvem jogos, atividades extraclasse, simulações, produções de materiais pedagógicos, questionários, minicursos, palestras e teatro (SATO, 2003, LUMMERTZ; FISCHER, 2017). A apropriação dessas ferramentas pela bioética de intervenção, provavelmente seja frequente, porém ainda incipientemente divulgadas. Rauli et al. (2018) organizaram uma obra sobre o uso de 
metodologias ativas no ensino superior da bioética destacando o uso da problematização, simulação, sala de aula invertida, trans narração, role playing, cinema e tecnologias digitais. No ensino básico, Fischer e Furlan (2017) trabalharam a temática "bem-estar-animal" usando vídeos, deliberação colaborativa e desenho. Fischer et al. (2017a, 2020a) propuseram trabalhar a EA não formal em confluência com a bioética em uma ação denominada "o caminho do diálogo" no qual estudantes do ensino básico debateram com mestrandos e docentes dilemas próprios de ambas as áreas. Artigas e Fischer (2019) incentivaram o fortalecimento do uso do zoológico como recurso didático para EA, uma vez que congregam inúmeras vulnerabilidades que não podem ser ensinadas como uma normalidade, e sim um conflito ético que deve ser mitigado.

Dentre as ferramentas artísticas exploradas pela EA destaca-se o teatro, uma vez que permite vivenciar virtualmente diferentes realidades, porém demanda um processo técnico próprio adaptável a diferentes públicos e propósitos. Contudo, Lummertz e Fischer (2017) alertaram que o educador deve ser capacitado para os desafios da utilização das ferramentas envolvendo as artes, ao intencionar promover a sensibilização e a catarse para um desenvolvimento efetivo, real e duradouro no educando. No contexto da BA o teatro igualmente passou a ser utilizado para conscientização, permitindo a maturidade moral e contribuindo para formação de pessoas críticas e ativas (SATO, 2003, FISCHER et al., 2017b).

No contexto educativo a comunicação é uma condição sine qua non cuja existência de ruídos, segundo Fischer et al. (2019), pode comprometer o diálogo entre os agentes morais. Partindo da concepção da bioética como uma ética prática, questiona-se como a área vem utilizando ferramentas para intervenções na realidade, na expectativa que haja uma relação temporal e geográfica atrelada às especificidades das distintas abordagens da bioética. Assim, o presente estudo testou as hipóteses:

a) Partindo do fato de que a bioética se constituir de uma ciência recente, espera-se que prevaleçam estudos teóricos, resultando em diferentes panoramas ao comparar o cenário nacional e internacional (DURHAM, 1993, PESSINI, 2007);

b) Entendendo o direcionamento prático da bioética de intervenção e da bioética na escola (GARRAFA, 2005), espera-se identificar o uso de ferramentas próprias associadas a temas e públicos específicos;

c) Considerando os diferentes propósitos e linguagens de comunicação científica e a necessidade de maior rigor e dados mais robustos na veiculação formal de um manuscrito, espera-se que os pesquisadores de bioética prática estejam predominantemente divulgando suas experiências em resumos de eventos científicos; 
d) Espera-se que no uso da arte como ferramenta de comunicação, predominem os recursos mais acessíveis, como o cinema, que não demandem domínio da técnica, tal como o teatro (LUMMERTZ; FISCHER, 2017).

Logo, o objetivo desta pesquisa foi avaliar as ferramentas de comunicação empregadas na bioética, por meio de uma revisão integrativa, bem como avaliar a confluência com a EA no propósito de construção de cidadãos críticos, autônomos e protagonistas.

\section{Metodologia}

\section{Revisão Integrativa}

A revisão integrativa foi realizada por meio de duas abordagens. $\mathrm{Na}$ primeira, o levantamento dos conteúdos científicos disponíveis na literatura foi obtido a partir do portal Google Acadêmico com o emprego dos descritores "bioética" e "bioethics". Como critério de inclusão foram recuperados os 100 primeiros artigos. Complementarmente foram incluídos 100 livros e 100 resumos de eventos científicos em bioética nacionais e internacionais, obtidos tanto por meio eletrônico quanto impresso e resgatado através de citações e referências dos próprios artigos analisados. Com intuito de comparação foi realizado o mapeamento do teatro como ferramenta educativa recuperando os 100 primeiros artigos que abordavam a temática "teatro na escola" disponível no portal Google Acadêmico e incluído 100 resumos de três congressos na área do teatro.

$\mathrm{Na}$ segunda abordagem, os textos científicos foram recuperados das bases Google Acadêmico e Portal da CAPES, a partir dos descritores "bioética de intervenção", "bioethics of intervention", "bioética na escola" e "bioethics at school'. Os critérios de inclusão foram os 100 primeiros registros, excluindo os repetidos.

\section{Categorização do Conteúdo}

Os dados relativos aos textos científicos foram categorizados considerando os critérios: a) data; b) abrangência; c) abordagens; d) públicoalvo; e) tema; f) fundamentação. Posteriormente, foram excluídos os conteúdos teóricos, sendo o conteúdo prático categorizado quanto: a) ferramentas utilizadas; b) pontos fortes; c) pontos fracos; d) avaliação. Então, foram excluídos os conteúdos que não utilizavam ferramentas de intervenção relativas as artes (visuais, música, dança, teatro e escrita).

\section{Processamento Estatístico}

Os valores absolutos foram comparados entre as categorias e entre as variáveis por meio do teste do qui-quadrado tendo como hipótese nula a distribuição homogênea a uma confiança de $95 \%(P<0,05)$ e um erro de $5 \%$. 


\section{Resultados}

\section{Bioética no cenário nacional e internacional}

A revisão integrativa das pesquisas sobre bioética totalizou a recuperação de 1.767 conteúdos científicos, compostos por 100 livros, 772 artigos e 895 resumos de eventos científicos. Os artigos recuperados indicaram que embora tenha sido mais frequentes no âmbito internacional, o pico de produção no exterior e no Brasil foi maior em 2010 com queda em 2016 (Figura 1).

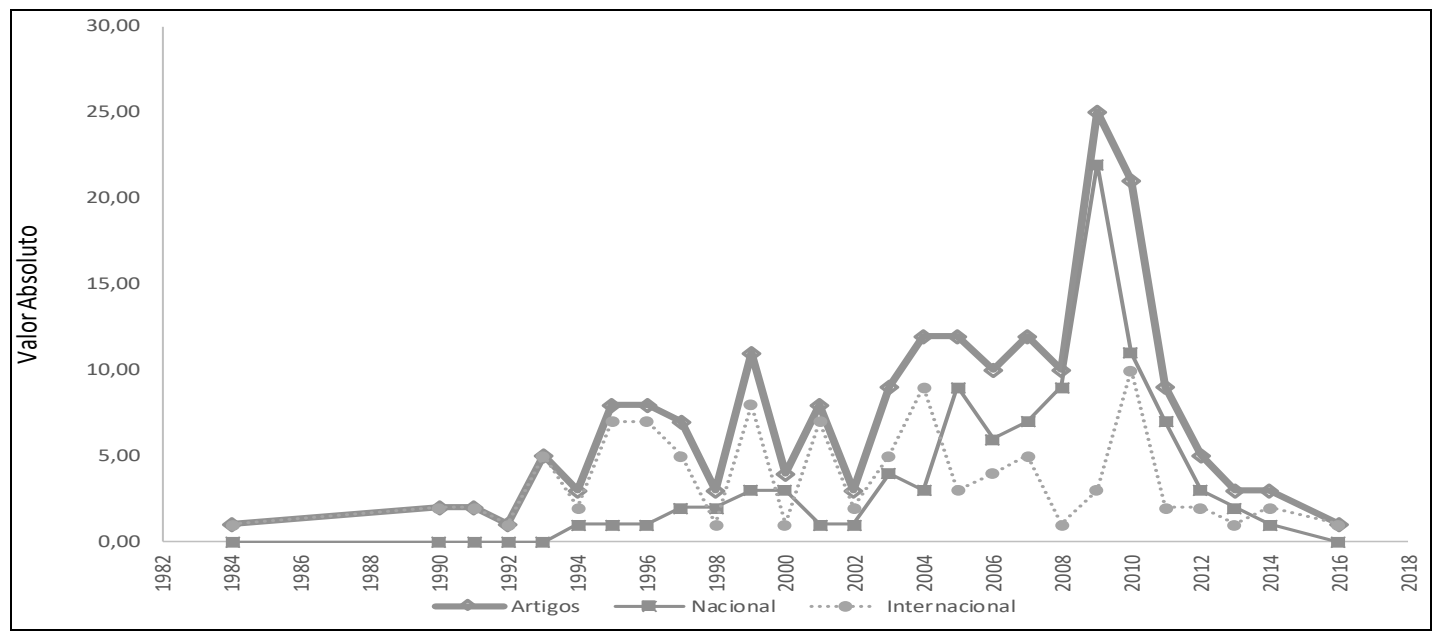

Figura 1: Valor absoluto de artigos científicos recuperados sobre bioética no total e âmbito nacional e internacional de 1982 a 2018.

Fonte: dados da pesquisa

Considerando a abordagem da bioética de intervenção e bioética na escola, o Brasil $(52,4 \%)$ se destacou a ser comparado a outros países $(47,6 \%)$, cujo pico de produção nacional foi entre 2010 e 2013 (Figura 2).

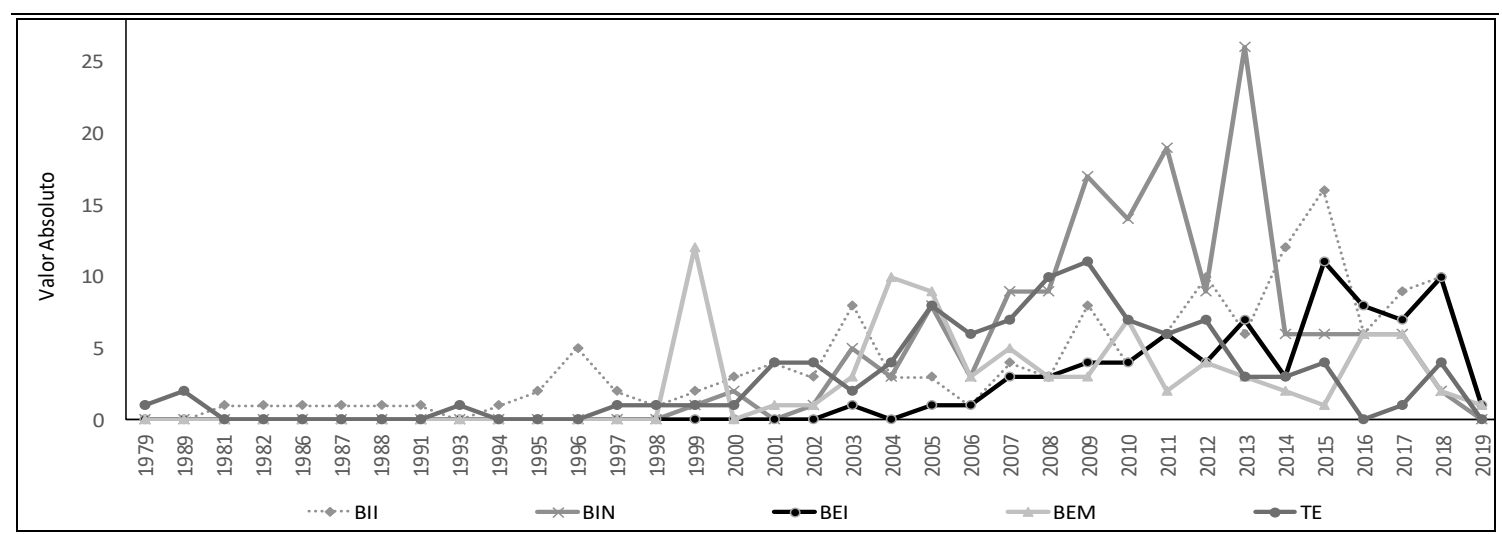

Figura 2: Valor absoluto de artigos científicos recuperados sobre bioética de intervenção (BI), bioética na escola (BE) e teatro na escola (TE) no âmbito nacional (N) e internacional (I) de 1979 a 2019.

Fonte: dados da pesquisa 


\section{Bioética no contexto teórico e prático}

A maioria dos textos científicos foi relativa a pesquisas teóricas (bioética: $84 \%$; bioética intervenção: $72 \%$ e bioética na escola: $63 \%)\left(\chi^{2}(1)=586\right.$; $\mathrm{P}<0,001)$, prevalecendo as pesquisas práticas no cenário nacional, principalmente em 2009 (Figura 3).

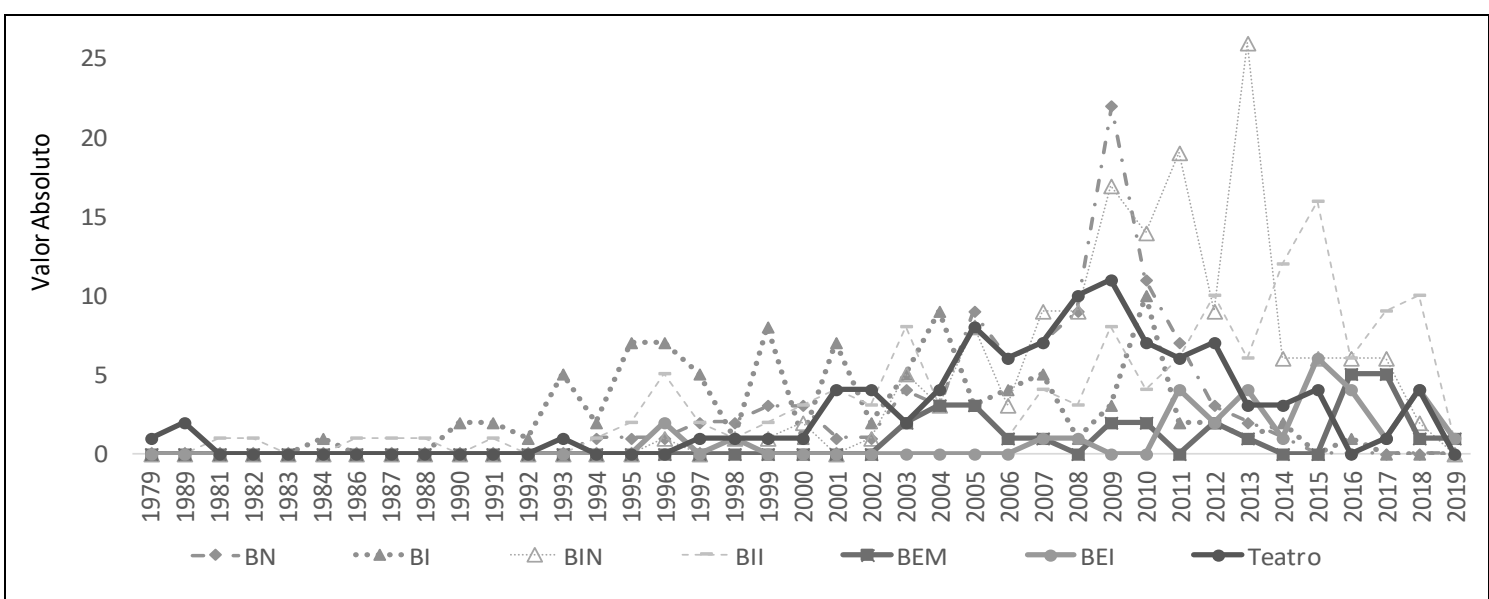

Figura 3: Valor absoluto de artigos científicos práticos recuperados sobre bioética (B), Bioética Intervenção $(\mathrm{BI})$, bioética na escola $(\mathrm{BE})$ e teatro na escola $(\mathrm{TE})$ no âmbito nacional $(\mathrm{N})$ e internacional (I) de 1979 a 2019.

Fonte: dados da pesquisa

\section{Veículo de divulgação bioética}

As pesquisas práticas e qualitativas em teatro, assim como as pesquisas práticas quantitativas em bioética foram mais frequentes em resumos de eventos. As ferramentas mais utilizadas em todos os veículos foram as entrevistas e os questionários, sendo as artísticas como o teatro mais frequente nos artigos. Os pontos fracos foram destacados apenas quanto à análise de conteúdo e discussão. O embasamento e a interdisciplinaridade foram os principais pontos fortes destacados nas pesquisas com teatro e debates, vivências e questões morais para bioética. Os poucos artigos que traziam a avaliação, se referiram à análise de conteúdo (Tabela1).

Tabela 1: Frequência relativa da categorização de artigos e resumos em bioética e teatro.

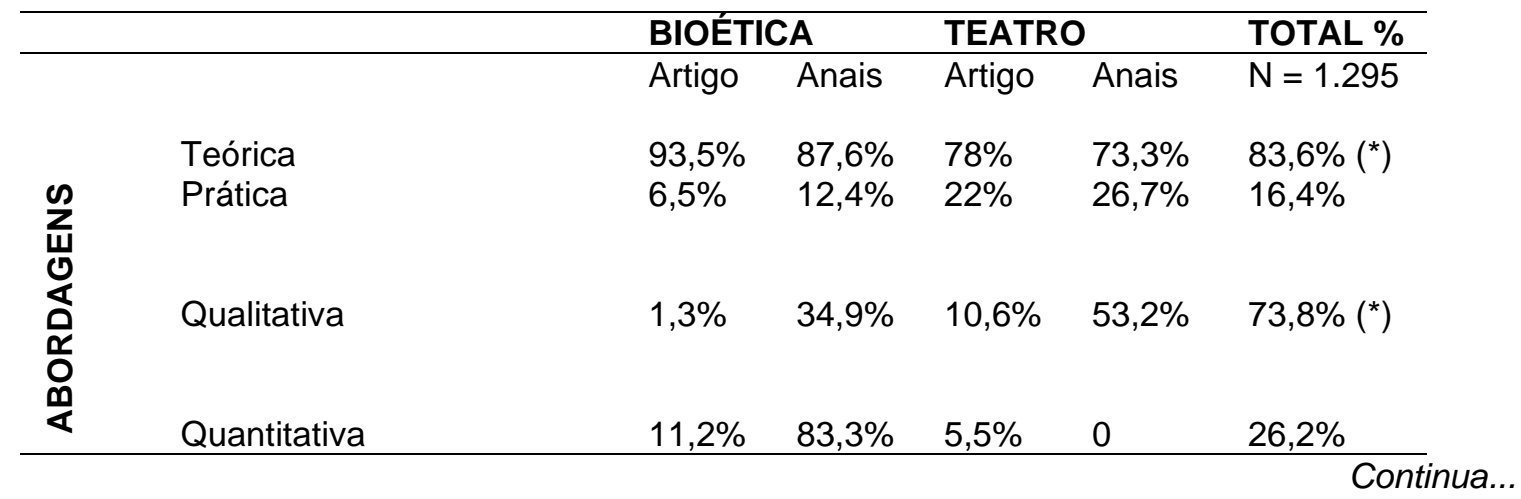

Revbea, São Paulo, V. 16, № 2: 69-87, 2021. 


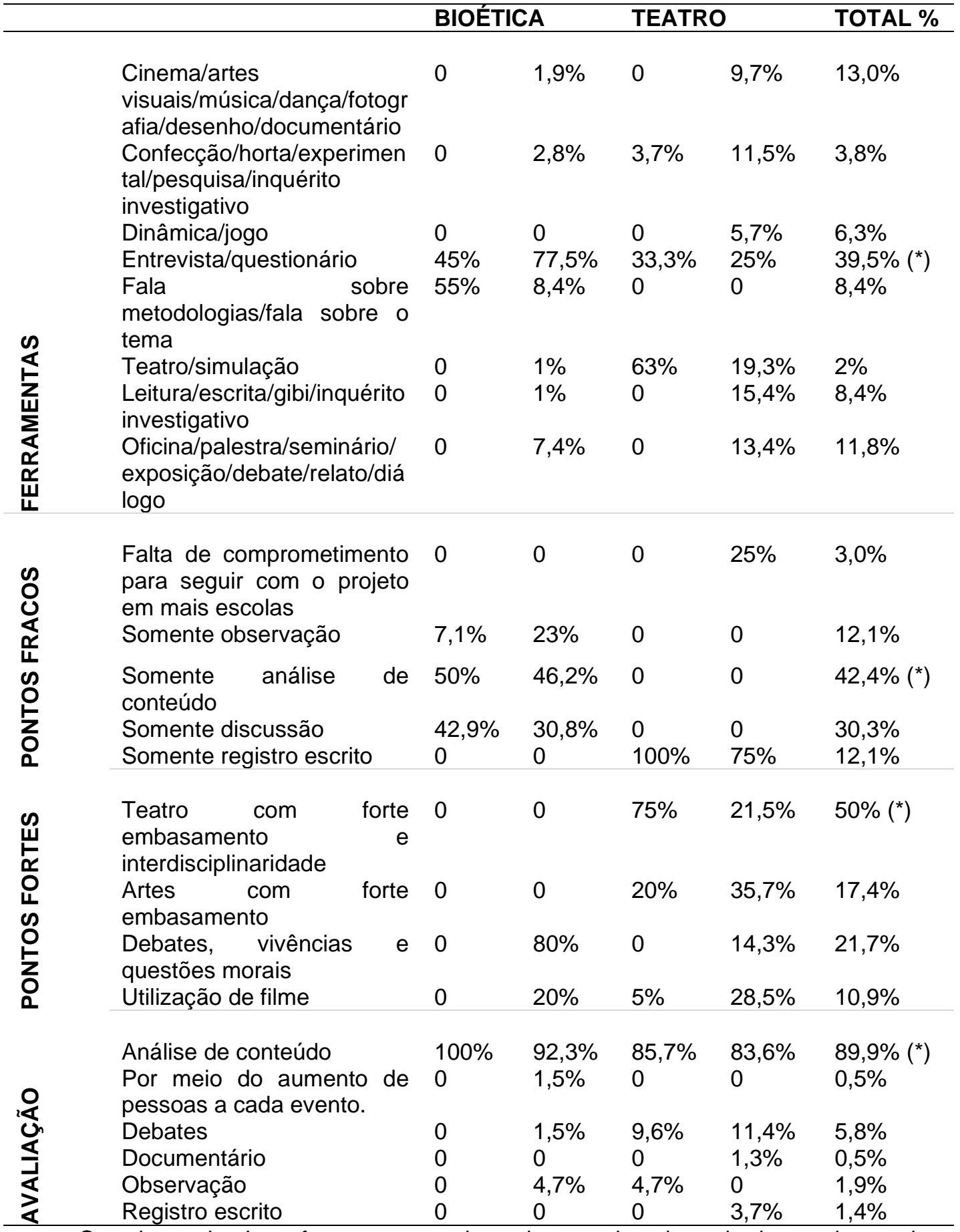

Os valores absolutos foram comparados pelo teste do qui-quadrado, sendo aqueles significativamente maiores acompanhados de asterisco $\left({ }^{*}\right)$.

Fonte: dados da pesquisa. 


\section{Público-Alvo na aplicação bioética prática}

O público-alvo predominante nas pesquisas com bioética e bioética na escola foram os profissionais, enquanto para bioética intervenção predominou a comunidade. Para teatro na escola, a maioria das intervenções foram direcionadas para estudantes do ensino básico (Tabela 2).

Tabela 2: Frequência relativa da categorização envolvendo bioética, bioética intervenção, bioética na escola e teatro na escola referente ao público-alvo.

\begin{tabular}{|c|c|c|c|c|c|}
\hline \multirow{6}{*}{ 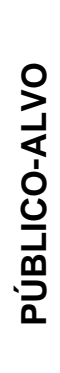 } & & BIOÉTICA & $\begin{array}{l}\text { BIOÉTICA } \\
\text { INTERVENÇÃO }\end{array}$ & $\begin{array}{l}\text { BIOÉTICA NA } \\
\text { ESCOLA }\end{array}$ & $\begin{array}{l}\text { TEATRO NA } \\
\text { ESCOLA }\end{array}$ \\
\hline & Profissionais & $46,4 \%\left(^{*}\right)$ & $26 \%$ & $40,6 \%$ & $1 \%$ \\
\hline & Comunidade & $19,6 \%$ & $54,1 \%\left(^{*}\right)$ & $15,6 \%$ & $11,6 \%$ \\
\hline & Professores & $1 \%$ & $2,3 \%$ & $1,5 \%$ & \\
\hline & $\begin{array}{l}\text { Estudantes Ensino } \\
\text { Básico }\end{array}$ & $6,2 \%$ & $5,9 \%$ & $22 \%$ & $62,1 \%$ \\
\hline & $\begin{array}{l}\text { Estudantes Ensino } \\
\text { Superior }\end{array}$ & $26,8 \%$ & $11,7 \%$ & $20,3 \%$ & $21,3 \%$ \\
\hline
\end{tabular}

Os valores absolutos foram comparados pelo teste do qui-quadrado, sendo aqueles significativamente maiores acompanhados de asterisco $\left({ }^{*}\right)$. Fonte: dados da pesquisa

\section{Temas utilizados na bioética prática}

Os temas de saúde predominaram nas intervenções na bioética e bioética intervenção, enquanto a escola e a educação predominaram na bioética na Escola e teatro na Escola (Tabela 3).

Tabela 3: Frequência relativa da categorização envolvendo bioética, bioética intervenção, bioética na escola e teatro na escola referente ao Tema.

\begin{tabular}{|c|c|c|c|c|c|}
\hline \multirow{7}{*}{$\underset{⿱ 乛}{\stackrel{\Xi}{\leftrightarrows}}$} & & BIOÉTICA & $\begin{array}{l}\text { BIOÉTICA } \\
\text { INTERVENÇÃO }\end{array}$ & $\begin{array}{l}\text { BIOÉTICA NA } \\
\text { ESCOLA }\end{array}$ & $\begin{array}{l}\text { TEATRO NA } \\
\text { ESCOLA }\end{array}$ \\
\hline & Ambiente & $1 \%$ & $7 \%$ & $3 \%$ & 0 \\
\hline & Educação & $43,5 \%$ & 0 & $1,4 \%$ & $95 \%\left({ }^{*}\right)$ \\
\hline & Escola & $1 \%$ & $3 \%$ & $66,6 \%\left(^{*}\right)$ & $2 \%$ \\
\hline & Saúde & $44,4 \%\left(^{*}\right)$ & $57,6 \%\left(^{*}\right)$ & $8,6 \%$ & 0 \\
\hline & Sociedade & $9,2 \%$ & $13 \%$ & $7,2 \%$ & $1 \%$ \\
\hline & Trabalho & $1 \%$ & $19,2 \%$ & $13 \%$ & $2 \%$ \\
\hline
\end{tabular}

Os valores absolutos foram comparados pelo teste do qui-quadrado, sendo aqueles significativamente maiores acompanhados de asterisco $\left({ }^{*}\right)$. Fonte: dados da pesquisa

\section{Ferramenta para uma bioética prática}

Nas pesquisas práticas referentes à bioética e bioética de intervenção, prevaleceu a utilização de métodos qualitativos $\left(\chi^{2}{ }_{(1)} 586 ; \mathrm{P}<0,001\right.$ e $\chi^{2}(1)=46$; $\mathrm{P}$ $<0,001$, respectivamente), predominando as entrevistas e questionários como 
ferramentas, enquanto que para teatro na escola prevaleceu os recursos áudio/visuais (Figura 4) .

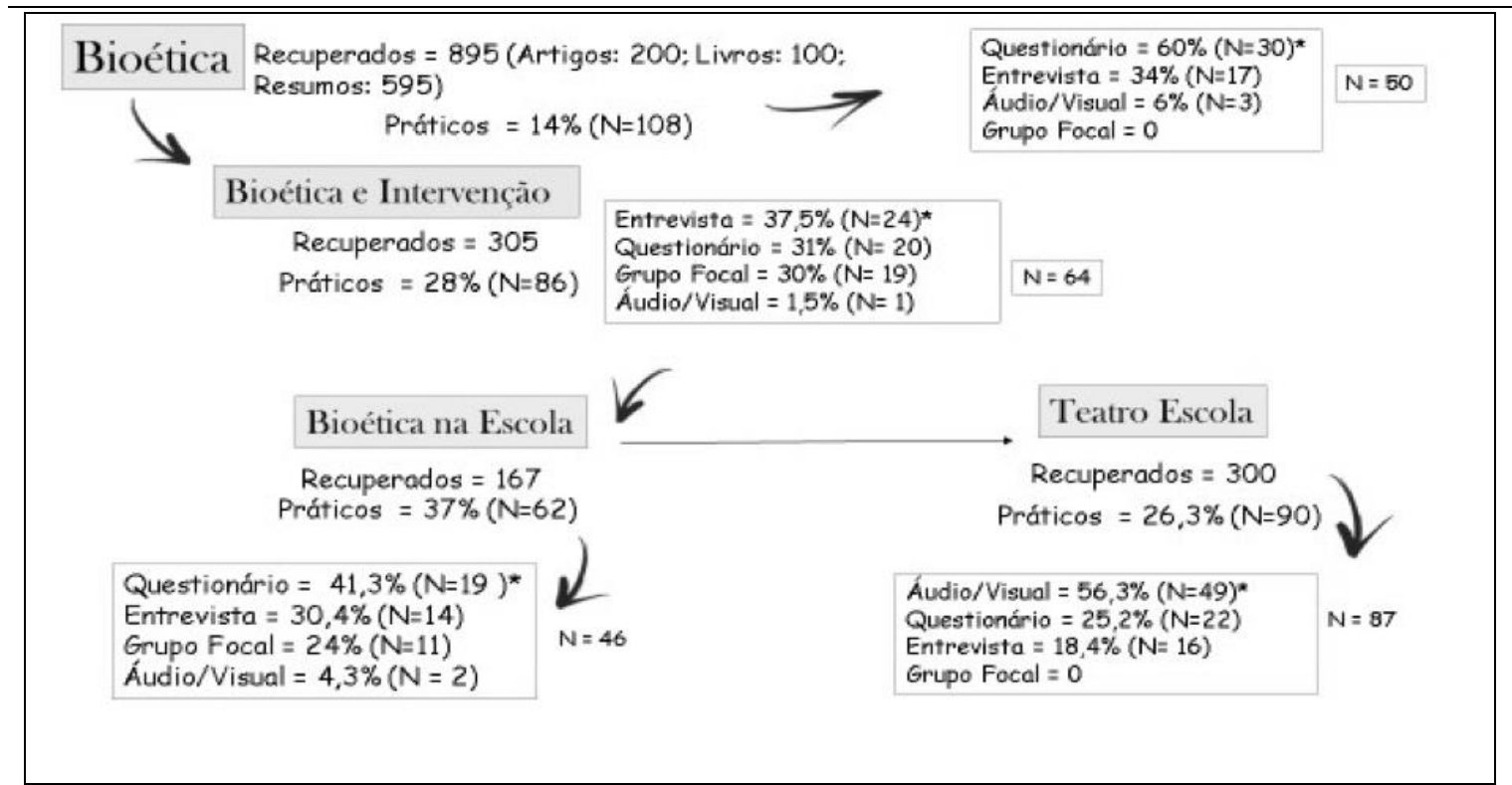

Figura 4: Fluxograma da categorização da Revisão Integrativa

Fonte: dados da pesquisa.

Artes como ferramenta da bioética prática: aplicação do teatro, cinema, simulação e atividades lúdicas na bioética

A análise qualitativa dos textos que abordavam as artes como ferramenta foi composta por três artigos, um resumo de congresso e dois capítulos de livro.

O estudo de Ladeira e Koifman (2017) intitulado "A terminalidade da vida no processo de ensino-aprendizagem em saúde", objetivou capacitar discentes de Fisioterapia utilizando o cinema como da fermenta. O filme adotado contava a história de um professor universitário com câncer terminal em seus últimos momentos de vida, estimulando a reflexão e permitindo a construção de fundamentação teórica. Os alunos foram divididos em grupos para que cada um relatasse suas impressões e, posteriormente as complementasse com pesquisas a respeito da terminalidade, eutanásia, distanásia e prolongamento da vida. Na sequência foi organizado um júri simulado, consolidando a metodologia por meio da problematização, propondo a elaboração de argumentos contrários e favoráveis aos temas abordados. A discussão foi balizada pelo professor que apresentava questões préelaboradas direcionando cada grupo a argumentar seu ponto de vista. Para a avaliação, foi considerada a participação individual e a produção de um portfólio relatando as impressões e dificuldades ao longo de cada etapa.

A obra "Bioética e metodologias ativas no ensino-aprendizagem" de Rauli et al. (2018) aborda o tema especificamente no capítulo "Bioética e cinema - um roteiro" (PARANHOS, 2017). A proposta prevê que os temas 
sejam expostos e discutidos, acompanhado de um caso real, sendo escolhido um filme referente a cada situação apresentada. Para discutir as diversas vertentes da ética, desde o utilitarismo até a filosofia de Kant, foi utilizado o filme "Crimes e Pecados". Já para abordar o Principialismo, a Bioética LatinoAmericana e trazer à discussão a indústria farmacêutica, empregou-se o filme "O Jardineiro Fiel". O debate sobre bioética clínica deu-se com o documentário "Solitário Anônimo". Para discutir a ética em pesquisa com humanos foi usado o filme "Cobaias Humanas", enquanto para o tema ética em pesquisa animal foi proposto o documentário "Não Matarás". Os autores não trazem dados a respeito de metodologia de avaliação. Segundo Paranhos (2017), o cinema e o teatro são meios eficazes de promover a catarse, que funciona como um eficaz meio de resolução de conflitos.

Além do cinema, a simulação vem sendo utilizada na formação de profissionais da saúde. O mesmo livro "Bioética e metodologias ativas no ensino-aprendizagem" também aborda a temática no capítulo "Aprendizagem baseada em simulação no ensino de bioética na formação médica". Montenegro et al. (2017) consideraram a simulação no contexto de metodologias ativas proporcionando subsídios para acadêmicos e profissionais de saúde. A simulação realística se utiliza da problematização como um instrumento transformador e permite que o aluno crie uma oportunidade de vivenciar uma experiência e resolver questionamentos reais. Segundo o autor, os adultos aprendem melhor quando estão ativamente envolvidos no processo, por isso a simulação reproduz aspectos essenciais em um cenário clínico para que, quando ocorrer em um contexto real, a situação possa ser gerenciada com sucesso. Montenegro et al. (2017) abordaram a experiência de um grupo de estudantes que participaram de atividades tradicionais e com simulação, atrelando resultados mais satisfatórios para metodologia inovadora. Para tal, foi apresentada para estudantes de medicina uma cena representando um casal com dificuldades financeiras que consideravam a possibilidade de aborto diante de uma gravidez indesejada. Os atores e estudantes receberam instruções previamente definidas e informações de seus personagens. Dessa forma, um cenário foi construído para representar um consultório médico real e a avaliação foi feita por meio da observação e do registro de pré-requisitos a serem cumpridos pelo estudante.

Atividades lúdicas como contação de história também são muito utilizadas na educação, principalmente com estudantes do ensino básico. A pesquisa de Souza e Shimizu (2013), intitulada "Representação social acerca dos animais e Bioética de Proteção: subsídios à construção da educação humanitária", trabalhou o método de grupo focal se apropriando da construção de uma história baseada em um trecho predeterminado. A partir da contextualização inicial, as crianças respondiam perguntas referentes à temática da pesquisa sendo os desfechos transcritos para posterior avaliação e análise. A atividade logrou despertar empatia nos estudantes por meio da história criada, em que o lúdico permitiu a construção de um raciocínio com base em múltiplas visões. 
A pesquisa de Gazzinelli et al. (2014) intitulada "Representações sociais de crianças participantes de um ensaio clínico sobre o pesquisador: de detentor do saber a crianças curiosas", também aplicou atividades lúdicas por meio da contação de história baseada no livro infantil "A Curiosidade Premiada" e adaptada para o ensaio clínico. A história foi contada por palhaços, inspirada no estilo Clown. A avaliação da pesquisa foi feita por meio da coleta de dados, da observação das falas, dos gestos e dos comportamentos, bem como de um questionário estruturado, aplicado antes e depois da intervenção. Outra forma de avaliação foi mediante confecção de desenhos realizados pelas crianças

\section{Discussão}

Os dados do presente estudo demostraram que a produção científica em bioética, todavia prioriza o contexto reflexivo sobre as urgências e preocupações relacionadas na relação entre pessoas e saúde. Contudo, há uma demanda de uma BA associada com a EA voltadas para compreensão e discussão dos problemas atuais oriundos do avanço tecnológico. Bem como no esforço no desenvolvimento de metodologias para balizar dilemas morais contemporâneos que envolvam o indivíduo, a sociedade e o ambiente.

O mapeamento temporal da produção científica em bioética evidenciou proporcionalidade entre o cenário nacional e internacional com pico em 2010. Porém, conforme o esperado, foi identificada menor produção no contexto nacional. A consolidação da bioética brasileira nas últimas décadas provavelmente foi impulsionada pela implementação do stricto sensu, atualmente ofertados em sete instituições: Pontifícia Universidade Católica do Paraná, Universidade Católica de Petrópolis, Universidade de Brasília, Universidade Metodista de São Paulo, Universidade Federal Fluminense, Universidade do Vale do Sapucaí e Fundação Oswaldo Cruz, sendo que a Universidade São Camilo encerrou seu mestrado em 2016. Esses resultados são suportados pelas inferências de Cruz e Chaimovich (2010), cujo número de programas de stricto sensu no Brasil duplicou entre 2000 e 2010, e de Cruz e Chaimovich (2010) e Durham (1993) de que o desenvolvimento das pesquisas no Brasil acompanhou a tendência internacional. Para Garrafa (2005), Pessini e Barchifontaine (2007) e Durham (1993) apesar das pesquisas em bioética no Brasil terem sido tardias, em comparação ao cenário internacional, acabou se recuperando com vigor a partir da criação dos grupos de pesquisa. Porém Durham (1993) ressaltou a importância da análise qualitativa das produções, uma vez que necessariamente o progresso científico não apresenta uma relevância social. Comparando com a EA, embora Fischer e Furlan (2018) tenham identificado picos de produção na mesma época da bioética, caracterizaram-na como essencialmente prática, cuja diversidade temática foi mais homogênea no âmbito internacional. Enquanto no Brasil ainda estava voltada para consolidação de técnicas pedagógicas, sendo que mais de $80 \%$ não apresentavam abordagem ética. Esse resultado elucida a 
complementariedade entre a vertente teórica e ética da bioética e natureza prática e pedagógica da EA, legitimando a sinergia entre as duas disciplinas.

A análise do conteúdo da produção científica recuperada atestou a expectativa de abordagens dissonantes entre o Brasil e o exterior. A suplantação de pesquisas com bioética de intervenção e bioética na escola no Brasil pode ser associada com interesse em questões urgentes de cunho social ao se comparar com a bioética norte-americana. Para Garrafa (2005), os macroproblemas bioéticos enfrentados pelos países latino-americanos, além de bastantes e diversos, muitos são persistentes e envolvem fortes índices de exclusão social. $\mathrm{O}$ autor fez um paralelo com o principialismo norte-americano, essencialmente voltado para questões de clínica médica, autonomia e respeito ao paciente. Essa disparidade também foi identificada por Fischer e Furlan (2018) para EA, cujas pesquisas que abordavam questões éticas e evidenciavam o público-alvo, diferenciavam o Brasil por abordar a equidade social, a inclusão e o utilitarismo voltados para sociedade. Esses resultados igualmente reiteram a sinergia da EA e da BA principalmente na realidade social e acadêmica nacional.

A essência teórica das pesquisas com bioética, em um primeiro momento, pode ser interpretada com o processo de consolidação próprio de áreas recentes. Para Nunes e Nunes (2004), as pesquisas direcionam discussões sobre questões conflituosas da humanidade que demandam uma fundamentação ética, não se mostrando, portanto, madura o suficiente para aplicar ferramentas apropriadas ou transpor o campo das ideias e atingir um patamar prático. $\mathrm{O}$ autor afirmou, ainda, que a bioética surgiu para resgatar as ciências humanas que estavam impregnadas com um pensamento individualista, influenciado e fortalecido pelo capitalismo, gerando discussões e reflexões acerca de como as áreas da ciência e da humanidade precisavam modificar concepções enraizadas. Contudo, deve-se considerar que a EA tem o mesmo tempo de percurso que a bioética e sua natureza prática sobressaiu (FISCHER; FURLAN, 2018), levando a expectativa que a associação com a EA possibilitará à bioética dar o salto para implementação de intervenções práticas demandada pela natureza de ética prática, lidar com conflitos urgentes e, principalmente, proporcionar mudanças no momento em que o problema está causando vulnerabilidades.

O predomínio das intervenções práticas no Brasil, ilustram a necessidade de países em desenvolvimento de executar soluções que amenizem questões básicas de sobrevivência. Garrafa (2005) pontuou o surgimento da bioética de intervenção como uma proposta conceitual de aliança concreta com o lado mais frágil da sociedade, evidenciando o coletivo e as políticas públicas que devem atender o maior número de pessoas possível. A superação da bioética principialista, para Garrafa (2005), se deu diante da sua incapacidade de proporcionar impactos positivos nas sociedades que são marcadas por grandes desigualdades. Complementarmente, Pessini e Barchifontaine (2007) reiteraram a necessidade de reflexão ética a respeito das dificuldades e frustações de populações menos favorecidas. Contudo, na

Revista brasileira educação ambiental 
ausência de metodologias e ferramentas que viabilizem essa intenção, tais como as próprias da EA (FISCHER; FURLAN, 2018), esses propósitos podem ser descredibilizados e considerados utópicos (FEITOSA; NASCIMENTO, 2015)

O predomínio dos relatos de intervenções práticas em bioética nos eventos científicos confirmou a hipótese inicial. De fato, o maior rigor e a exigência por dados e análises mais robustas se constituem de barreiras para o pesquisador transpor a sua experiência em um artigo científico. Fischer e Molinari (2016) mapearam os resumos apresentados em congressos de bioética alertando para existência de propostas inovadoras e com potencial transformador, que não se consolidavam por ficarem restritas a esses espaços. Corroborando os autores, embora se vislumbre a relevância desse momento científico, restringir a divulgação das pesquisas ao contexto informal atrasa a consolidação da área, pois não valida as propostas inovadoras. De acordo com Pizzani et al. (2010), o conhecimento científico depende de publicações em periódicos científicos, fortalecendo a edição científica como linha de pesquisa para assim contribuir com estudos na área da bioética, campo jovem e em desenvolvimento. Os periódicos determinam o desenvolvimento das pesquisas e delimitam o campo científico, pois são validados por autores, editores e avaliadores, direcionando e decidindo assuntos relevantes a cada área ou campo científico. Os pesquisadores argumentam a incipiência de periódicos, principalmente qualificados, para veiculação dos resultados. De fato, a Coordenação de Aperfeiçoamento de Pessoal de Nível Superior (CAPES, 2020) tem cadastrados 16 periódicos com chamadas diretas para bioética, sendo três nacionais e apenas quatro nos extratos A: American Journal of Bioethics (A1 medicina), Bioetica y Derecho (A2 direito) e Jounal of Bioethcal Inquiry (A2 educação). Paralelamente, a cada dois anos ocorrem três congressos oficiais em bioética no Brasil: Congresso Brasileiro de Bioética (CBB), que já está em sua XIII edição; o Congresso Luso-Brasileiro de Bioética (CFM), o qual está em sua XI edição; e o Congresso Ibero-Americano de Bioética, em sua II edição. Para EA são registrados nove periódicos específicos, demonstrando que a confluência das áreas traria mais possibilidades para ambas.

A produção em bioética e educação se mostrou associada, todavia ao contexto universitário e de formação continuada. Compreensível, segundo Sanches e Souza (2008) devido a necessidade de consolidação da área, formação de multiplicadores e de instrumentalização de profissionais que precisam empregar a bioética na sua na prática diária, principalmente na saúde. Sendo que cursos como medicina, biomedicina, enfermagem, ciências biológicas incorporaram a bioética em seus currículos com 0 intuito de estimular condutas humanizadas na resolução de dilemas morais (FISCHER et al., 2017a). Contudo, desponta no meio científico propostas de intervenções no ensino básico (FISCHER et al., 2017b, 2020a). Fischer et al. (2020b) justificaram a necessidade da associação entre a BA e a EA como meio de promoção da biofilia, uma teoria defendida por Edward Wilson (WILSON, 1993) 
de que os seres humanos dependem do contato com a natureza para seu bemestar físico, mental e espiritual. A deficiência de contato com os elementos naturais já está sendo associada a uma desordem pedagógica denominada de déficit de natureza (DICKINSON, 2013). Contudo, os dados da pesquisa acrescido da análise dos temas de EA abordados nas escolas (ARTIGAS, FISCHER, 2019) não evidenciam a inclusão de questões éticas e morais envolvidas no cuidado com o ambiente. Fischer et al. (2016, 2017a, 2018, 2019) e Loureiro (2009) reiteraram que é fundamental direcionar ações educacionais ao público infanto juvenil pela importância dessa fase na formação e no desenvolvimento de valores, bem como na personalidade, na consciência crítica e autônoma, permitindo uma mudança efetiva no comportamento e nas atitudes.

A prevalência dos questionários e das entrevistas como ferramentas de intervenção inicialmente parece atrelada ao fato da bioética ser uma ciência nova, na qual se faz necessário a caracterização da temática para o públicoalvo. Pessini e Barchifontaine (2007) e Feitosa e Nascimento (2015) afirmaram que a urgência em solucionar os conflitos bioéticos demandam que as pesquisas envolvendo intervenção em bioética se apropriem de ferramentas que permitam analisar opiniões e os anseios da população. No entanto Fischer et al. (2019) para EA identificaram o uso de instrumentos de intervenção e avaliação em apenas 5,6\% dos 1525 artigos analisados. Assim como Lummertz e Fischer (2017) e Artigas e Fischer (2019) para EA identificaram predomínio do uso de questionários e análises qualitativas e escassez do uso de ferramentas tecnológicas. Certamente, que o diagnóstico da percepção do público é fundamental como pontuado por Fischer et al. (2017c) para um planejamento, aplicação e avaliação das práticas de EA. Contudo além de considerar que essas ferramentas também demandam de processos técnicos próprios para elaboração e análise que atentam sua integridade, se conclama por técnicas inovadoras para as intervenções e avaliação. Fischer et al. (2019) frisaram que mesmo para o público jovem as intervenções em EA ainda estão subutilizando os processos tecnológicos, cuja acessibilidade e identificação poderia reverter em resultados mais efetivos (FISCHER et al., 2020b).

As ferramentas lúdicas foram direcionadas principalmente para as crianças, segundo Boal (2002) apesar da intrínseca sua relevância na educação e aproximação com o universo infantil, deve ser impermeada por técnicas próprias para garantir a sua efetividade pedagógica. Indubitavelmente deve-se investir na ludicidade e na descontração, tais como as envolvidas em muitas intervenções de EA, como a visita ao zoológico (ARTIGAS, FISCHER, 2019). Não deve ser desconsiderada a descontração do processo educativo, pois segundo Lummertz e Fischer (2017) e Sato (2003) é um facilitador para o desenvolvimento cognitivo. Porém, não deve ser destituída da bagagem teórica, do planejamento e da avaliação, para que a intervenção seja contextualizada e acompanhe o programa de aprendizagem proposto. O teatro, embora ainda configurando incipientemente nas veiculações científicas é amplamente utilizado pela EA (LUMMERTZ, FISCHER, 2017) apoiado no 
histórico de ferramenta de comunicação BERTOLD 2005). Porém, aparte do seu componente familiar e lúdico, Boal (2002) ressaltou que se constitui de uma ferramenta que exigem embasamento teórico, pois existem métodos que devem ser seguidos para se alcançar diferentes resultados. A necessidade de capacitação do educador foi apontada por diferentes pesquisadores como Lummertz e Fischer (2017), Durmaresq et al. (2009), Sato (2003) e Fischer et al. (2019), cujo descomprometimento e aplicação baseada em vivências ou senso comum podem culminar em resultados desfavoráveis.

A utilização do cinema e da simulação como ferramentas, embora incipientes nas pesquisas recuperadas, foram pontuadas na obra organizada por Rauli et al. (2018) com um alto potencial de aplicação no uso da bioética no ensino superior, uma vez que proporcionam vivências e discussões pertinentes à realidade. Paranhos (2017) e Montenegro et al. (2017) avaliaram a aplicação para os cursos de medicina e enfermagem atestando que criaram subsídios por meio da problematização e colocaram o estudante diante de situações factíveis de ocorrerem durante a sua atuação profissional. Ressalta-se que a possibilidade de errar em suas decisões é uma propriedade da simulação, que permite ao agente moral voltar a trás e reverter sua escolha, sem comprometer o outro, diferente da realidade.

\section{Conclusões}

A análise da revisão integrativa, proporcionada por essa pesquisa, identificou que embora haja confluência de valores e interesses entre a BA e a EA há disparidade em relação às abordagens e temáticas. Ambos os aspectos legitimam a sinergia das disciplinas a fim de potencializar o impacto positivo na sociedade em termos de mudanças de conduta em prol de uma existência melhor e mais justa para pessoas e natureza. O perfil teórico da BA tem muito a ganhar com as intervenções práticas e com a diversidade de ferramentas utilizadas no planejamento, condução e avaliação da EA. Embora essas ferramentas ainda sejam incipientes e demandem investimento de pesquisa e tecnologia, serão impulsionadas com a associação com as questões éticas e morais que originam os conflitos sociais. A EA e a BA dispõem do mesmo tempo de percurso, almejando reparação das necessidades de forma consciente, justa e igualitária. A BA agrega à EA em decorrência principalmente do aumento de complexidade dos problemas com potencial de geração de vulnerabilidades, particularmente devido as decisões serem concomitantemente tomadas por inúmeros agentes morais (FISCHER, FURLAN, 2017). Por outro lado, no ambiente escolar a EA igualmente intenciona conduzir o estudante à compreensão da importância de saber ouvir sem julgamentos os argumentos do outro, encontrar soluções consensuais e justas e através da reflexão permitir o protagonismo imediato. Portanto, é importante e urgente que a bioética seja incorporada na educação em qualquer nível de ensino, nos contextos formal e não formal, e em todas as situações que se necessite de reflexões éticas, a fim de priorizar conflitos envolvendo o 
coletivo. Para Fischer et al. (2019) a BA e EA se confluem na vida como valor comum e no propósito de educar os cidadãos para que o cuidado com a natureza seja um projeto compartilhado, vislumbrando a sinergia de ambas na construção de ferramentas que viabilize a formação do educador ambiental, a aplicação eficiente das intervenções e a construção do cidadão.

A expectativa de amadurecimento da bioética prática no contexto educativo superior, básico ou não formal não é condizente nem com o tempo de existência da área, nem com a perspectiva social própria de países em desenvolvimento, embora tenha se detectado uma tendência. Logo, vislumbrase a transposição efetiva da bioética teórica para bioética prática a partir da somatória da trajetória, experiência e penetração política da EA. Contudo, se faz necessário que mais pesquisas sejam desenvolvidas e incentivadas a criação de práticas inovadoras, factíveis e adaptáveis e que elas sejam divulgadas em diferentes meios de comunicação populares e científicos. Porém, que igualmente sejam concebidas como ciência, para que desta forma ferramentas de prospecção, aplicação e avaliação sejam validadas, principalmente as tecnológicas e artísticas, pois permitem vivências e catarses que proporcionam ao educando se colocar inteiramente na situação e visualizar as consequências de suas decisões. Esse estudo vem agregar a outras pesquisas conduzidas pelo grupo de Pesquisa em Bioética Ambiental que propõe a construção e consolidação de um comitê de Bioética Ambiental nas escolas (FISCHER, FURLAN, 2017b; FISCHER et al., 2019, ARTIGAS; FISCHER, 2019), estabelecendo um ambiente acolhedor, normatizador, consultivo, deliberativo, educativo e multidisciplinar, composto por professores, gestores, estudantes, comunidade e academia, que juntos determinem as questões urgentes e viabilizem a bioética prática em confluência com EA com intuito de formar cidadãos críticos, autônomos e conscientes do seu papel de agente e paciente moral e mitigador de vulnerabilidades.

\section{Referências}

ARTIGAS, N.A.S.; FISCHER, M.L. O Zoológico como recurso didático para Educação Ambiental. Revista Brasileira de Educação Ambiental, v. 14, p.219-239, 2019.

BERTHOLD, M. História do Teatro. Rio de Janeiro: Perspectiva, 2005.

BOAL, A. O Arco-Íris do Desejo, Método Boal de Teatro e Terapia. Rio de Janeiro: Civilização Brasileira, 2002.

BRASIL. Lei n 9.795, de 27 de abril de 1999, Da Educação Ambiental. Brasília, DF; Presidência da República. Acessado em 28 fevereiro de 2020. Disponível em http://www2.mma.gov.br/port/conama/legiabre.cfm?codlegi=321. Acesso 25 mar 2020.

CAPES. Qualis.caps.gov.br. 2020. Disponível em: <www.periodicos-capes-govbr>. Acesso 19 fev 2021. 
CRUZ, B.; CHAIMOVICH, H. Brasil. Relatório Unesco sobre ciência. Unesco. p.35-55, 2010.

DICKINSON, E. The misdiagnosis: Rethinking nature-deficit disorder. Environmental Communication. A Journal of Nature and Culture, v. 7, p.315335, 2013.

DURMARESQ, M.I.A.; PRIEL, M.R.; ROSITO, M.M.B. A Educação Bioética no ensino Fundamental: Um Estudo a Partir da LDB e do PCN. Contrapontos, (n.2), p.66-79, 2009.

DURHAM, E.R. Uma Política para o Ensino Superior. São Paulo: NUPES, 1993.

FEITOSA, S.F.; NASCIMENTO, W.F. A Bioética de intervenção no contexto do pensamento latino-americano contemporâneo. Revista Bioética. v.23, p.277284, 2015.

FISCHER, M.L.; CASTRO-JUNIOR, H.T.; SPITZENBERGENE, B.A.K.; ARTIGAS, N.A.S.; LUMMERTZ, T.B. Educação Ambiental e Bioética Ambiental: Uma Reflexão a Partir dos Instrumentos de Avaliação. Rev. Intersaberes. v.14, p.594-609, 2019.

FISCHER, M.L.; CUNHA, T.R.; LUMMERTZ, T.B.; MARTINS, G.F. Caminho do Diálogo II: Ampliando a Experiência Bioética para o Ensino Médio. Revista Bioética, v. 28, n. 1, 47-57. 2020a

FISCHER, M.L.; CUNHA, T.; RENK, V.; SGANZERLA, A.; SANTOS, J.Z. Da Ética Ambiental à Bioética Ambiental: Antecedentes, trajetória e perspectivas. História, Ciências e Saúde de Manguinhos. v.24, p.391-409, 2017a.

FISCHER, M.L. CUNHA, T.R.; ROTH, M.E.; MARTINS, G.Z. Caminhos do diálogo: uma Experiência Bioética no Ensino Fundamental. Revista Bioética. v.25, p.89-100, 2017b.

FISCHER, M.L.; MOLINARI, R.B. Bioética Ambiental: A Retomada do Cunho Ecológico da Bioética. In: SGANZERLA, A., SCHRAMM, F.R. Fundamentos da Bioética série Bioética vol. 3, Curitiba:CRV, p.233-253, 2016.

FISCHER, M.L.; MOSER, A.M.; FURLAN, A.L.D. Bioética e Educação: a Utilização do Nivelamento Moral como Balizador para Construção de um Agente Moral Consciente, Autônomo e Reflexivo. In: Renk, V. (org). Bioética e educação: Múltiplos Olhares. p.33-67, 2016.

FISCHER, M.L.; FURLAN, A.L.D. Bioética e Educação: Concepção da Terminologia Bem-Estar-Animal por Estudantes do Ensino Básico. Revista Brasileira de Pesquisa em Educação em Ciências, v.17, p. 399-422, 2017.

FISCHER, M.L., FURLAN, A.L.D. Interfaces Entre a Bioética Ambiental e a Educação Ambiental in Sganzerla et al. (org) Bioética ambiental. Curitiba:PUCPRESS, 2018. 
FISCHER, M.L.; PAROLIN, L.C.; VIEIRA, T.B.; GARBADO, F.R.A. Bioética Ambiental e Educação Ambiental: levantando a reflexão a partir da percepção. Revista Brasileira de Educação Ambiental, v. 12, p. 58-84, 2017b.

FISCHER, M.L., ZANATTA, A.M., FURLAN, A.L.D., ARTIGAS, N.R.S., SANTOS-JR, R.J.; LUMMERTZ, T.B. A sinergia da biofilia e da Educação Ambiental: a inserção da bioética no ensino básico. In: RENK, V. (org). Bioética e educação: multiplos olhares. vol. II. Curitiba:CRV, p. 65-84, 2020c.

GARRAFA, V. Da Bioética de Princípios a uma Bioética Interventiva. Revista Bioética., v.13, p.125-134, 2005.

GAZZINELLI, M.F.C.; SOUZA, V.; PEREIRA, F.B.; ARAUJO, L.H.L.; FERNANDES, M.M.; MELO, P.F.; COSTA, R.M. Representações sociais de crianças participantes de um ensaio clínico sobre o pesquisador: de detentor do saber a crianças curiosas. Saúde Soc. v.23, p.582-591, 2014.

GOLDIM, J.R. Bioética: origens e complexidade. Rev. HCPA. v. 26, p.86-92, 2006.

LADEIRA, T.L.; KOIFMAN, L. A Terminalidade da Vida no Processo de EnsinoAprendizagem em Saúde. Anais XII Congresso Brasileiro de Bioética, Recife: IMIP, 2017

LOUREIRO, C.F.B. Trajetória e Fundamentos da Educação Ambiental. São Paulo: Cortez, 2009.

LUMMERTZ, T.B; FISCHER, M.L. O Teatro como Ferramenta de Promoção de Educação Ambiental. Revista Brasileira de Educação Ambiental, v.12, p.5672, 2017.

MONTENEGRO, A.P.; SANCHES, G.A.; MELLO, R.G.; SANCHES, L.C. Aprendizagem Baseada em Simulação no Ensino de Bioética na Formação Médica. In: RAULI et al. (org) Bioética e Metodologias Ativas no EnsinoAprendizagem. Curitiba: Editora CVC, 2017.

NUNES, C.R.R.; NUNES, A.P. Bioética. Revista Brasileira de Enfermagem., v.57, p.615-616, 2004.

ONU. Declaração Universal sobre Bioética e Direitos Humanos, 2005. Disponível em: <http://bvsms.saude.gov.br/bvs/publicacoes/declaracao univ bioetica dir hum.pdf>. Acesso em 25 mar 2020.

PARANHOS, F.R.L. Bioética e Cinema - Um Roteiro. In: RAULI et al. (org.) Bioética e Metodologias Ativas no Ensino-Aprendizagem. Curitiba: Editora CRV, p.133., 2017.

PESSINI, L. BARCHIFONTAINE, C.P. Problemas Atuais da Bioética. São Paulo: Loyola, 2007.

PIZZANI, L. SILVA, R.C. HOSSNE, W.S. Análise bibliométrica dos 40 anos da produção cientifica em Bioética no Brasil e no mundo. Revista BioEthikos., p.453-460, 2010. 
POTTER, V.R. Bioética: Ponte para o futuro. São Paulo: Edições Loyola, 2016.

RAULI, P.M.F.; SANCHES, L.C.; MELLO, R.G.; ZAGONEL, I.P.S.; COELHO, I.C.M.M. Bioética e Metodologias Ativas no Ensino-Aprendizagem. Curitiba: Editora CRV, 2018

SANCHES, M.A; SOUZA, W. Bioética e sua Relevância para a Educação. Rev. Diálogo Educacional., v.8, p.277-287, 2008.

SATO, M. Educação Ambiental. São Carlos: J.E. Rima, 2003.

SOUZA, J.F.J.; SHIMIZU, H. E. Representação social acerca dos animais e Bioética de proteção: subsídios à construção da educação humanitária. Revista Bioética., v.21, p.546-560, 2013.

SCHRAMM, F.R. A Bioética, seu desenvolvimento e importância para as Ciências da Vida e da Saúde. Revista Brasileira de Cancerologia., v.48, p.609-615, 2002.

UNESCO. Declaración de la Red Latinoamericana y Del Caribe de Educación em Bioética de Unesco, La Habana, 2019. Disponível em: $<$ http://redlaceb.com/>. Acesso 25 mar 2020.

WILSON, E.O.; KELLERT, S.A. Biophilia and the Conservation Ethic. Washington, D.C: The Biophilia Hypothesis, 1993.vou ver o que consigo 